\title{
DESIGN AND EVALUATION OF AN OPTIMAL FUZZY PID CONTROLLER FOR AN ACTIVE VEHICLE SUSPENSION SYSTEM
}

\begin{abstract}
Summary
The goal of studying the vehicle suspension systems is to reduce the vehicle vibrations which are due to the irregularities of road levels and the fluctuations in the vehicle velocity. These vibrations are transferred to the body and occupants of vehicles through the suspension system. In general, the main function of an active suspension system is to support the vehicle body by reducing the input vibrations and to provide a safe and smooth ride on a bumpy road surface. In this research, a quarter vehicle model has been employed for designing a suspension system. The road level irregularities have been considered as disturbances to this system. The optimal fuzzy PID (OFPD+I) controller has been used to optimize the performance of the suspension system in reducing the adverse effects resulting from road level irregularities, vehicle braking, and moving around the road curves. To verify the efficacy of the optimal fuzzy PID controller, its performance has been evaluated and compared with the performances of three separate controllers (PID, fuzzy, and fuzzy PID) and a system without any controller. The findings indicate the advantage of the optimal fuzzy PID controller over the other systems. Thus, in the integral of the absolute error criterion for the vehicle body velocity and displacement changes, the OFPD + I controller has a superior performance relative to the other systems.
\end{abstract}

Key words: $\quad$ Genetic Algorithm, Active Suspension System, Quarter Vehicle Model, Optimal Fuzzy Proportional-Integral-Derivative (PID) Controller

\section{Introduction}

The suspension mechanism is an important system in vehicles. The design of vehicle suspension systems is a field research into a component that directly affects the comfort and safety of the passengers and reduces vibrations, whether those arising from the car engine or those from the road irregularities [1]. In most mechanical systems, it is often necessary and useful to separate the disturbing forces [2]. The suspension system refers to a set of springs, shock absorbers, and leverages which are attached to the wheels of a vehicle. If roads were completely smooth, there would be no need for a suspension system. However, this is not the case; and the rough road levels exert continuous impact forces on the car wheels. All these impact forces are eventually transferred to the car cabin and the passengers, causing the vibration of the vehicle body and quick wear and deterioration of its parts. The suspension 
systems in vehicles are generally divided into three categories: passive or inactive suspension systems, semi-active suspension systems, and active suspension systems. In a passive suspension system, it is important to tune the damping coefficient and the spring constant to achieve a safe and comfortable ride. In the design of this type of suspension system, there is a contradiction between the ride safety and the comfort. The ride comfort is obtained by minimizing the vibrations of the vehicle body; the ride safety is achieved by increasing the area of contact between the car wheels and the road surface. An inactive suspension system is not able to simultaneously improve both of these aspects; therefore, engineers usually make a compromise between these two factors in order to design a proper suspension system. On the other hand, an active suspension system can simultaneously achieve both the ride safety and the ride comfort, but at a higher cost and by utilizing more power. Various control strategies are used for controlling the suspension system of vehicles; the most common and widely-used schemes among them are Proportional-Integral-Derivative (PID) and fuzzy controllers. In the last several decades, numerous researchers have worked on the control of vehicle suspension systems. In the following, some of these research studies are cited. In 2007, Khajavi et al. analysed the performance of a fuzzy controller in controlling a suspension system and compared it with the performance of a passive system. The authors considered the reaction velocity of the suspension system and the velocity of the suspended mass as the inputs for the fuzzy controller and the damping coefficient as its output. The results obtained for their proposed controller indicated a considerable reduction in overshoot [3]. In 2007, Hada et al. investigated a suspension system by employing a half vehicle model with 4 degrees of freedom. The authors proposed a control scheme for force elimination, which led to the separation of the suspended mass from the unsuspended mass. To provide stability for the suspended and unsuspended masses, they used a virtual damper along with a skyhook damper. Parameters such as 'damping coefficient' and 'spring stiffness' were optimized by means of genetic algorithm to strike a balance between vehicle handling, ride quality, and driving comfort. By applying the genetic algorithm, they improved the driving quality [4]. In 2013, Lie studied an adaptive nonlinear suspension model by using a fuzzy controller. The examined model was an active half-vehicle model. The author demonstrated that the responses of his proposed controller are better than those of an uncontrolled system [5]. In 2013, Shio et al. developed a self-tuning fuzzy controller for the suspension system of a quarter car model. The performance of the controller was simulated and analysed in stepped and pulsed road conditions. That fuzzy controller achieved an improvement of $63 \%$ in the amplitude of suspended mass displacement [6]. In 2013, Wang et al. formulated a selfadaptive fuzzy PID controller. In that suspension system, the changes in the dynamics, velocity and acceleration of the vehicle body had been integrated with the used feedback. The simulated suspension system with the self-adaptive fuzzy PID controller showed a significant improvement in the comfort and stability of drives over road surface irregularities [7]. In 2014, Aggarwal conducted a study on a semi-active suspension system by employing a quarter car model with 3 DOF. He used a fuzzy controller with two inputs and one output for controlling the suspension system. The simulation was performed for a road bump input with a height of $5 \mathrm{~cm}$. The simulation results indicated the advantage of the fuzzy controller over the suspension system without any control [8]. A review of various papers shows that, among different control methods used for vehicle suspension systems, the PID and fuzzy controllers, as basic control strategies, have the best performance. Although the PID controller is a widely used controller with unique characteristics, this controller has certain drawbacks, including the difficulty in tuning its parameters finely. The other controller with a superior status among other control systems is the fuzzy controller. Like other controllers, the fuzzy controller also has its advantages and disadvantages [9]. One of the most important advantages of this controller is its resistance to system uncertainties and disturbances; this characteristic has 
earned it the reputation of a controller with inherent robustness [10]. However, besides this unique feature, a shortcoming that may be considered in relation with this controller is the need for sufficient linguistic experience and understanding required for extracting fuzzy rules, which is one of the steps in designing a fuzzy controller. The aim of this research is to design an optimal fuzzy PID controller for controlling the suspension system in a quarter car model and isolating the vehicle from the vibrations it experiences. In fact, by combining a PID controller with intelligent fuzzy logic, a fuzzy PID controller with the unique characteristics of both the PID and fuzzy controllers is achieved. The PID controller improves the static and dynamic performances of the control system. Also, the smart fuzzy controller helps resolve the uncertainties of the controller mathematical model and provides a kind of robustness for the control system. The genetic algorithm is used to tune the scaling parameters of the controller in order to optimize its performance. Among methods available for combining the PID controller with the intelligent fuzzy logic, the optimal fuzzy PD+I (OFPD+I) controller is selected to be used in this research. In order to demonstrate the effectiveness of the proposed controller, its performance is evaluated and compared with the performances of three separate controllers (PID, fuzzy, and fuzzy PID) and of a system without a controller.

\section{Mathematical model for the active vehicle suspension system}

A quarter car model with 2 degrees of freedom is used for the examined suspension system. In this model, the masses of the car and its accessories are considered as the suspended mass, and the masses of the tyres and their fixtures are considered as the unsuspended mass. The active suspension system of the vehicle can be modelled as a linear spring and a damper together with an actuator between these two masses. Also, the tyres can be modelled as a linear spring and a damper. With regards to the physical properties of a tyre, its damping coefficient is usually disregarded. Figure 1 and Table 1 show the quarter model and parameters of the active vehicle suspension system [11].

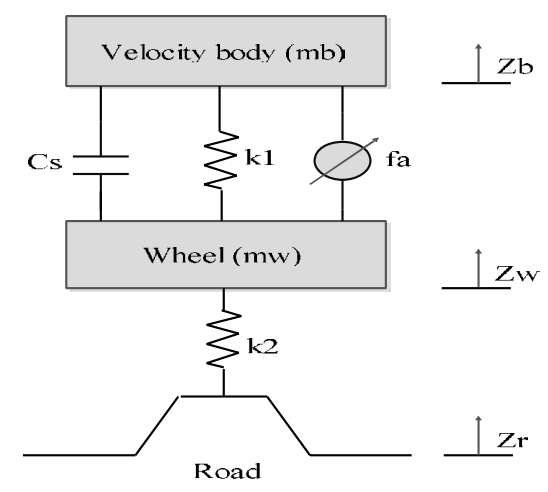

Fig. 1 A quarter model of the vehicle suspension system [11]

Table 1 Parameters of the quarter car model [12]

\begin{tabular}{|c|c|c|}
\hline Parameter & Definition & Value \\
\hline$m_{\mathrm{b}}$ & Vehicle body mass & $295 \mathrm{~kg}$ \\
\hline$m_{\mathrm{w}}$ & Tyre mass & $45 \mathrm{~kg}$ \\
\hline$c_{\mathrm{s}}$ & Damping coefficient & $1000 \mathrm{Ns} / \mathrm{m}$ \\
\hline$k_{1}$ & Spring constant & $16000 \mathrm{~N} / \mathrm{m}$ \\
\hline$k_{2}$ & Tyre stiffness coefficient & $160000 \mathrm{~N} / \mathrm{m}$ \\
\hline $\mathrm{f}_{\mathrm{a}}$ & Acting force & - \\
\hline
\end{tabular}


The displacements of the vehicle body and wheels in the vertical direction are denoted by $\mathrm{z}_{\mathrm{b}}$ and $\mathrm{z}_{\mathrm{w}}$, respectively, and $\mathrm{z}_{\mathrm{r}}$ is the disturbing road input. By applying Newton's second law, the governing equations of the suspension system (Figure 1) are expressed as follows [12]:

$$
\begin{aligned}
& \mathrm{m}_{\mathrm{b}} \ddot{\mathrm{z}}_{\mathrm{b}}=\mathrm{f}_{\mathrm{a}}-\mathrm{k}_{1}\left(\mathrm{z}_{\mathrm{b}}-\mathrm{z}_{\mathrm{w}}\right)-\mathrm{c}_{\mathrm{s}}\left(\dot{\mathrm{z}}_{\mathrm{b}}-\dot{\mathrm{z}}_{\mathrm{w}}\right) \\
& \mathrm{m}_{\mathrm{w}} \ddot{\mathrm{z}}_{\mathrm{w}}=-\mathrm{f}_{\mathrm{a}}+\mathrm{k}_{1}\left(\mathrm{z}_{\mathrm{b}}-\mathrm{z}_{\mathrm{w}}\right)-\mathrm{k}_{2}\left(\mathrm{z}_{\mathrm{w}}-\mathrm{z}_{\mathrm{r}}\right)+\mathrm{c}_{\mathrm{s}}\left(\dot{\mathrm{z}}_{\mathrm{b}}-\dot{\mathrm{z}}_{\mathrm{w}}\right)
\end{aligned}
$$

\section{Designing an optimal fuzzy PD+I controller}

The combination of a fuzzy controller and a PID controller will create a fuzzy PID controller. Three factors including an input error, an integral error, and a derivative error can be used as variable inputs of fuzzy controller into one fuzzy PID controller. It is perfectly clear that a fuzzy rule base by three inputs will be really huge. In addition, extraction of the rules related to the integral action will be hard and troublesome [9]. Therefore, the separation of integral action from fuzzy rules for creating a fuzzy PID will seem much more appropriate. In this research, the optimal fuzzy $\mathrm{PD}+\mathrm{I}(\mathrm{OFPD}+\mathrm{I})$ controller has been considered for the combination of PID and fuzzy controllers. In the optimal fuzzy PD+I controller, the error and error derivative inputs have been used as the variables of the fuzzy controller. The block diagram of the OFPD $+\mathrm{I}$ controller is given in Figure 2 [9]. Control signal $\mathrm{U}(\mathrm{t})$ is represented by equation 3 [9].

$$
\mathrm{U}(\mathrm{t})=\mathrm{f}\left[\left(\mathrm{Ge} * \mathrm{e}(\mathrm{t})+\mathrm{Gce} * \frac{\mathrm{d}}{\mathrm{dt}} \mathrm{e}(\mathrm{t})\right)\right] * \mathrm{Go}+\mathrm{Gie} * \int \mathrm{e}(\mathrm{t}) \mathrm{dt}
$$

The parameters present in the control signal of equation 3 are listed in Table 2.

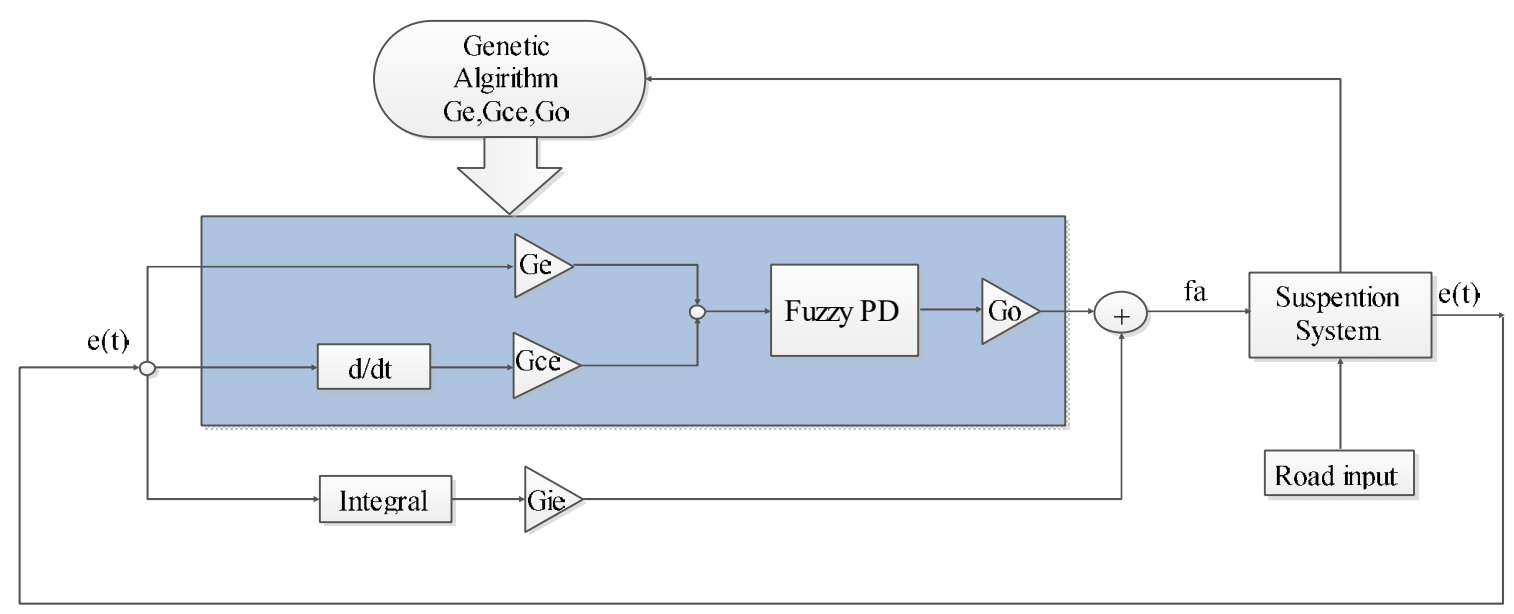

Fig. 2 Model of the OFPD + I controller [9]

Table 2 Control signal parameters [9]

\begin{tabular}{|l|c|}
\hline Definition & Parameter \\
\hline Error resulting from the impact caused by road level irregularities & $\mathrm{e}(\mathrm{t})$ \\
\hline Input error scale factor for the FPD controller & $\mathrm{Ge}$ \\
\hline Input error derivative scale factor for the FPD controller & $\mathrm{Gce}$ \\
\hline Scale factor of the FPD output & Go \\
\hline Input integral error scale factor & Gie \\
\hline
\end{tabular}




\section{Extracting the fuzzy rules}

The important point in designing the fuzzy control of an active suspension system is to determine the control rules and the membership functions so that the system can perform satisfactorily. This section deals with the extraction of rules for designing the FPD $+\mathrm{I}$ controller, without considering the structure of the suspension system and only with the help of the system step response. The response of the suspension system to a step input (impact caused by the vehicle hitting a road bump of a height of $10 \mathrm{~cm}$ ) is illustrated in Figure 3 [9].

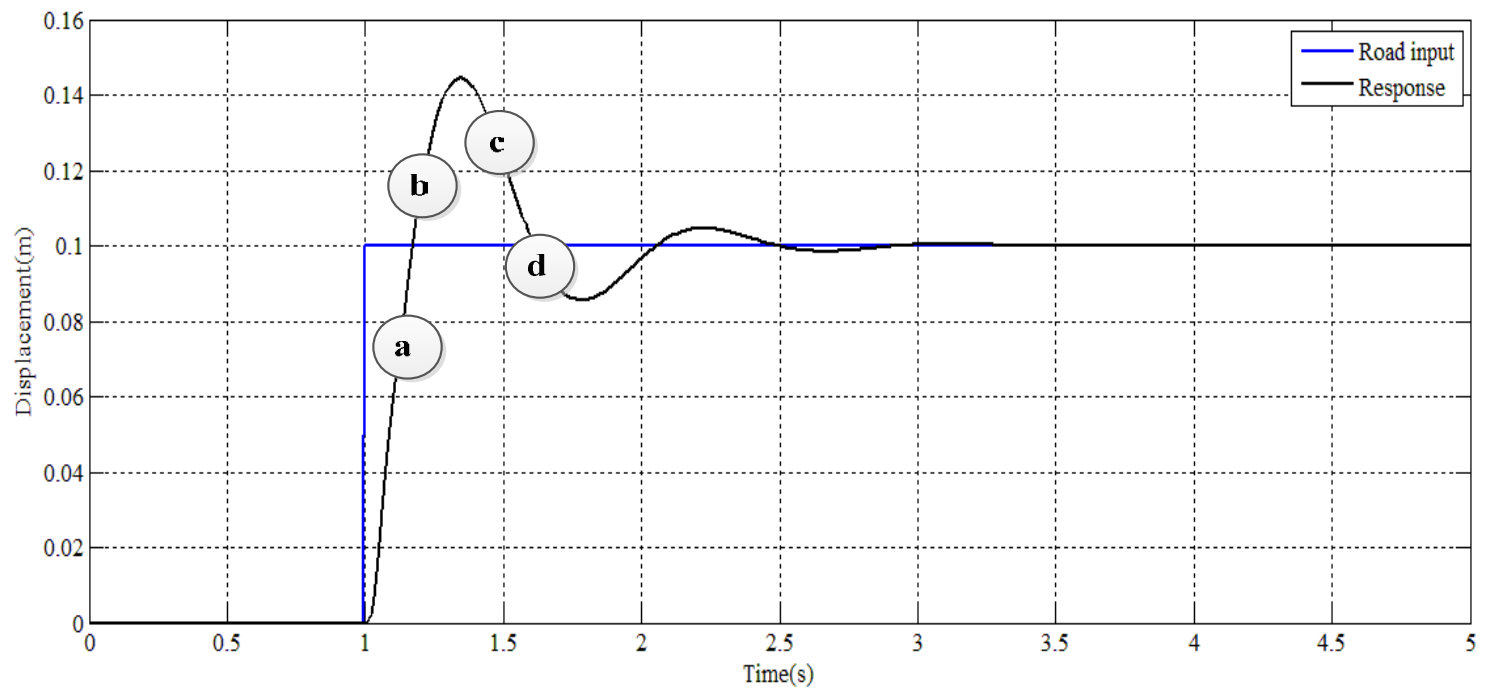

Fig. 3 Stepped oscillations of the vehicle body due to the impact caused by the vehicle hitting road level irregularities [9]

In Figure 3, the system response is divided into different parts; in each part, the control force that must be applied to the system by the actuator is specified. Therefore, for different behaviours exhibited by the system, appropriate controller and actuator reactions can be determined [9]. By using the fuzzy membership functions, each of the input variables is converted from a numerical frame to a fuzzy (linguistic) frame. The membership functions for the variables of vehicle body velocity, vehicle body displacement and actuator force are shown in Figures 4-6 [13].

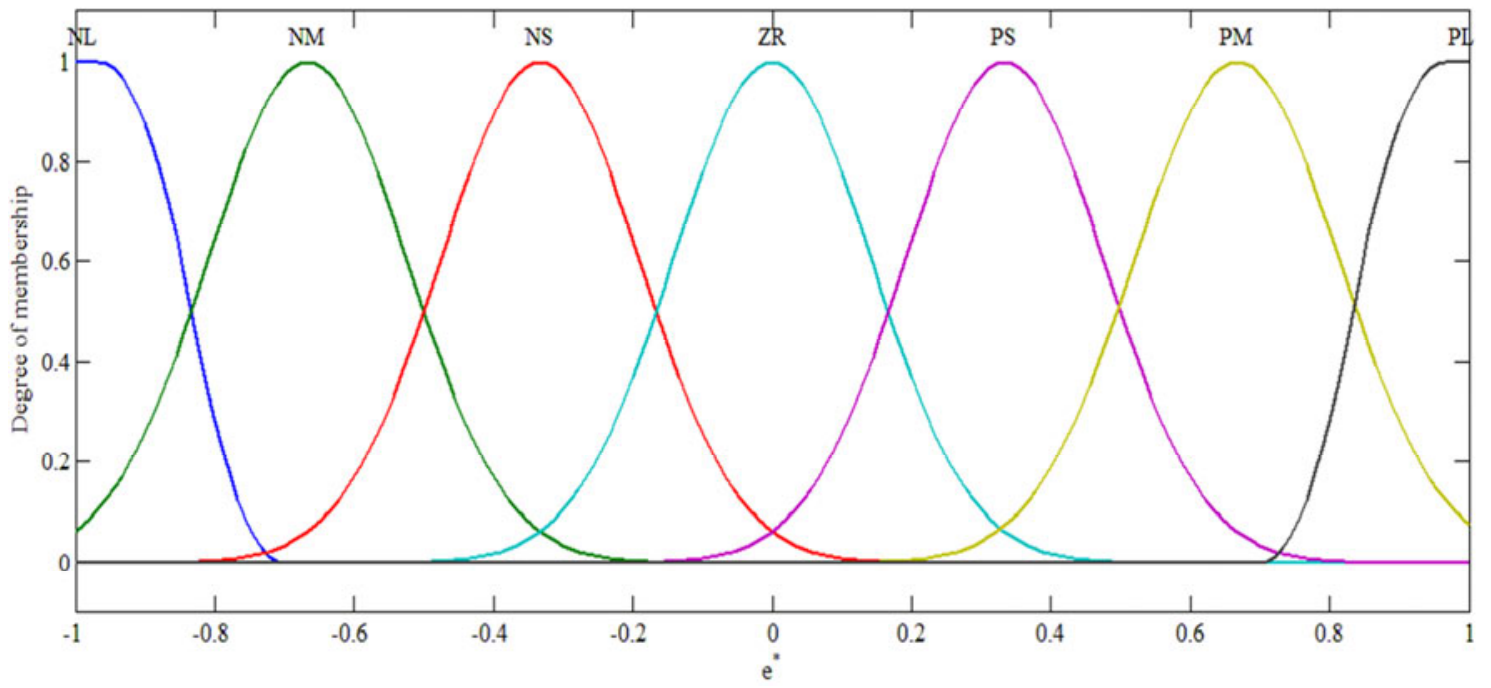

Fig. 4 Membership function for the vehicle body velocity (e') [13] 


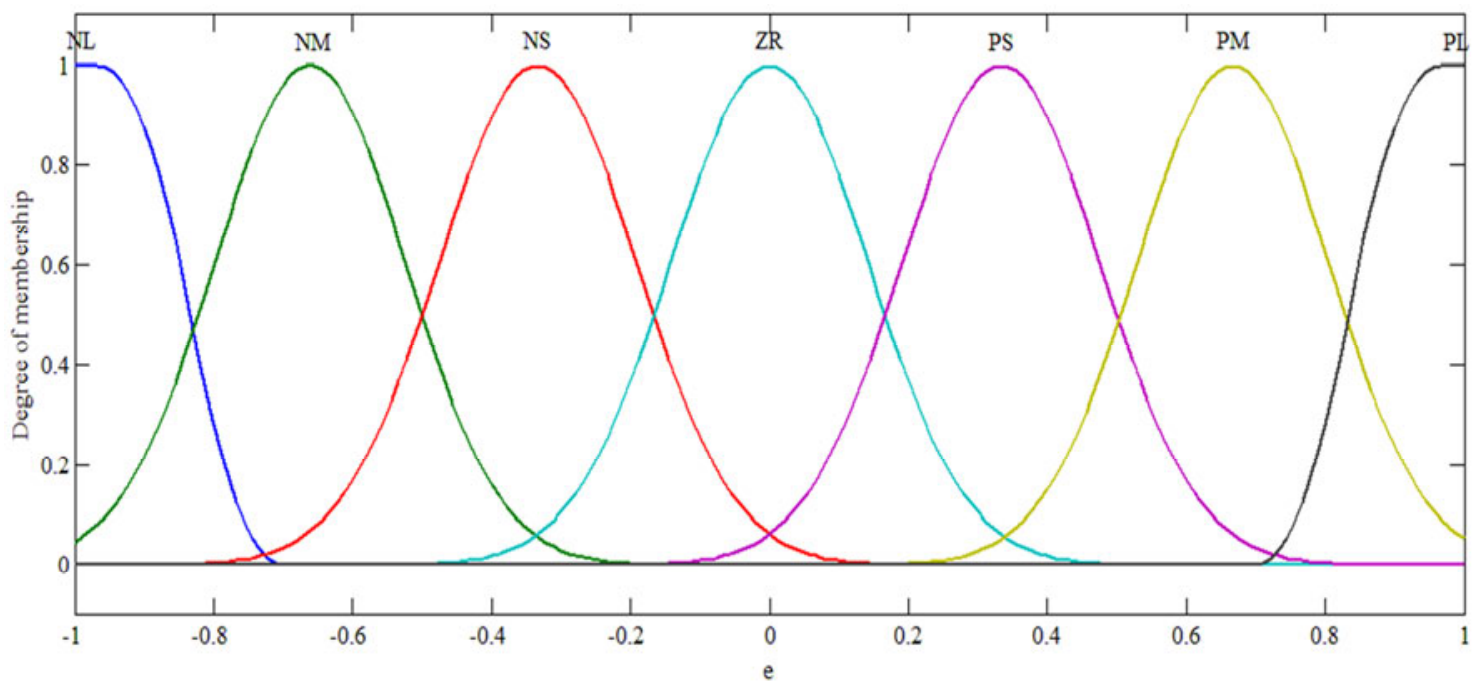

Fig. 5 Membership function for the vehicle body displacement (e) [13]

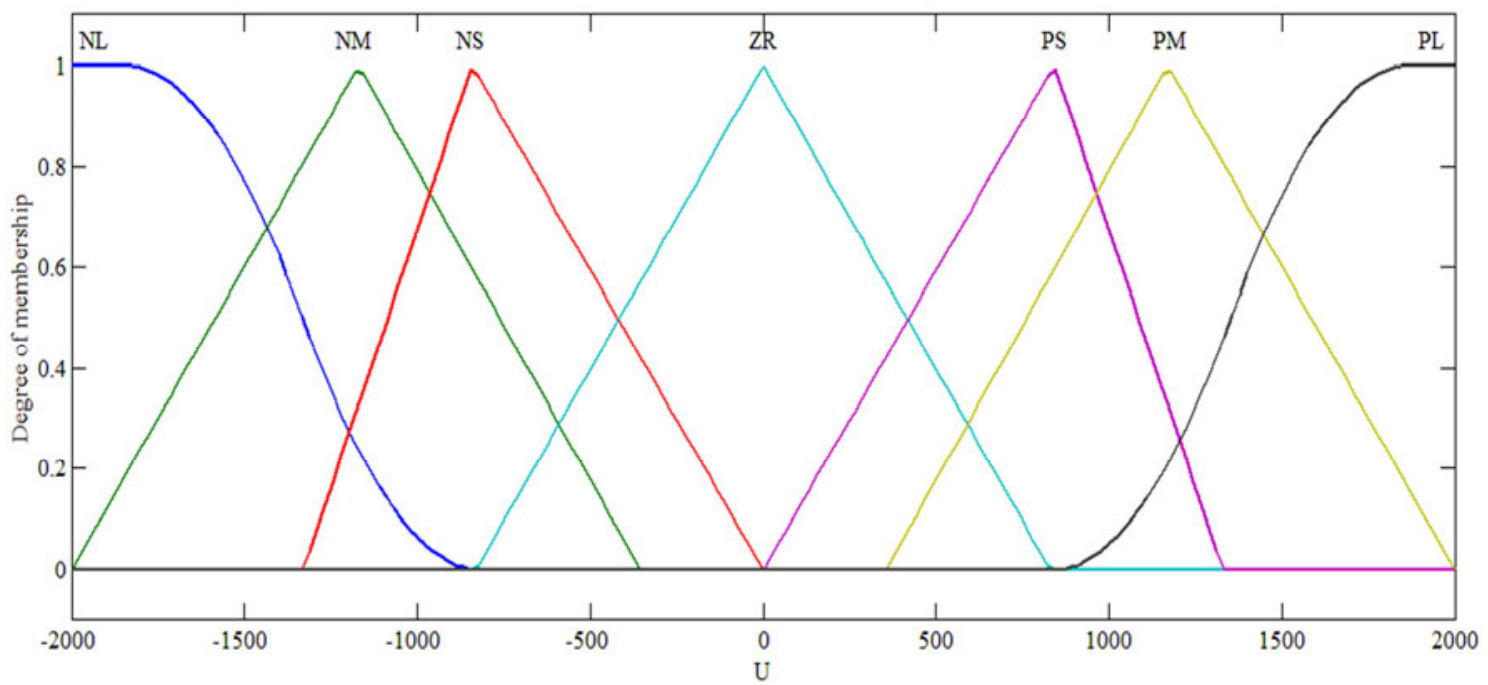

Fig. 6 Membership function for the control output $\left(f_{a}\right)$ [13]

In this controller, the "AND" operator with "Minimizing" logic has been used for combining the conditions, and a "Mamdani" type search engine has been selected for the fuzzy system. In designing the fuzzy PID controller, 49 rules in the form of "IF-THEN" have been used as the fuzzy rules base. The fuzzy rules base which can be used for the fuzzy PID controller of an active suspension system is presented in Table 3 [13, 14].

Table 3 The fuzzy rules base for the fuzzy PID controller [13, 14]

\begin{tabular}{|c|c|c|c|c|c|c|c|c|}
\cline { 2 - 9 } \multicolumn{1}{c|}{} & \multicolumn{7}{c|}{ change } \\
$\begin{array}{c}\text { of } \\
\text { error }\end{array}$ & & NL & NM & NS & ZR & PS & PM & PL \\
\cline { 2 - 9 } & PL & ZR & PS & PM & PL & PL & PL & PL \\
\cline { 2 - 9 } & PS & NS & ZR & PS & PM & PL & PL & PL \\
\cline { 2 - 9 } & ZR & NL & NM & ZR & PS & PM & PL & PL \\
\cline { 2 - 9 } & NS & NL & NL & NM & NS & ZR & PS & PM \\
\cline { 2 - 9 } & NM & NL & NL & NL & NM & NS & ZR & PS \\
\cline { 2 - 9 } & NL & NL & NL & NL & NL & NM & NS & ZR \\
\hline
\end{tabular}


Table 4 Abbreviated designations used in the fuzzy rules [15]

\begin{tabular}{|c|c|}
\hline NL & Negetive large \\
\hline NM & Negetive medium \\
\hline NS & Negetive small \\
\hline ZR & Zero \\
\hline PS & Positive small \\
\hline PM & Positive medium \\
\hline PL & Positive large \\
\hline
\end{tabular}

\section{Genetic algorithm with binary coding}

Coding is one of the key concepts of the genetic algorithm; this concept should be implemented more accurately than the other operating factors or design parameters of the algorithm. The genetic algorithm is based on converting each solution set to a code, which is known as a chromosome. The genetic algorithm comes in various types such as genetic algorithm with real coding, genetic algorithm with binary coding, saw-tooth genetic algorithm, micro genetic algorithm, improved genetic algorithm, and differential evolutionary genetic algorithm. The most usual method of representing the chromosomes in the genetic algorithm is in the form of binary strings. The genetic algorithm with binary coding has been employed in this research. In the binary coding method, based on an iterative probabilistic search, a set (population), which, for example, can consist of binary character strings of constant lengths, is converted to a new population of offsprings by using Darwin's natural selection principle and the operations that naturally occur in genetic procedures [9].

\section{Optimizing the controller by means of the binary genetic algorithm}

The genetic algorithm is used to optimize the three coefficients of $G_{e}, G_{c e}$ and $G_{0}$. These three coefficients are defined as the scaling coefficients of the input and output variables of the FPD controller and they play a very important role in the performance of the controller. In fact, these coefficients directly affect the Universe of Discourse (UOD) interval of membership functions (see Figure 7) [9].

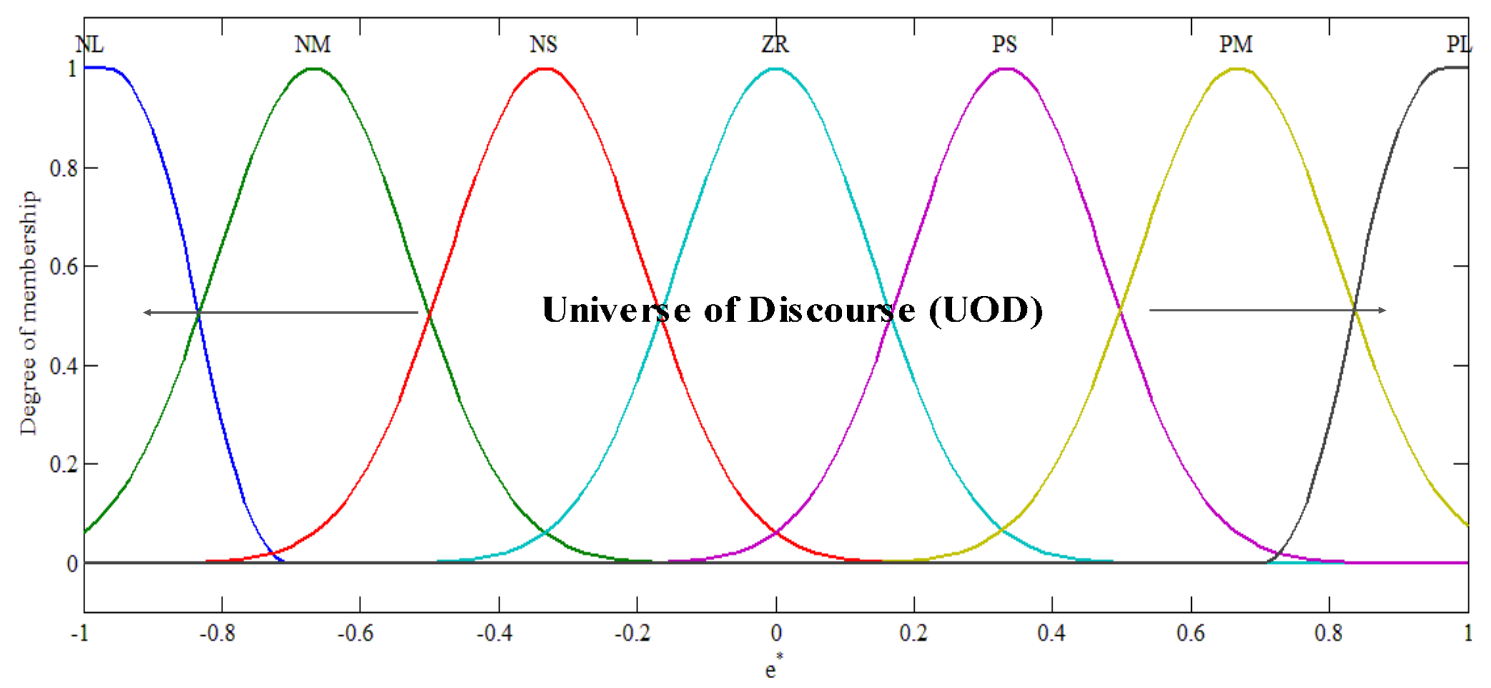

Fig. 7 The UOD interval over the membership functions [9] 
The scaling coefficients greatly influence the performance of the fuzzy controller; thus, if the scaling coefficients are not selected properly, the performance of the active suspension system might become even worse than that of a passive system. Therefore, these coefficients must be chosen in such a way as to achieve the best possible performance. The UOD range varies in proportion to the scaling coefficients. For example, since Gaussian membership functions have been used as the input variables of the controller, for each membership function, two parameters can be defined, according to equation 4 [9].

$$
f(x)=\exp \left(\frac{-0.5(x-c)^{2}}{\sigma^{2}}\right)
$$

Parameter $c$ is the mean value of the membership function, and $\sigma$ is its variance. Therefore, the optimization of the scaling coefficients actually constitutes the choosing of optimal values for the mean and variance parameters $(c$ and $\sigma)$ of the FPD controller input membership functions [9]. The fitness function for the genetic algorithm is expressed as

$$
\text { Fitness Function }=\int_{0}^{\mathrm{T}}|\mathrm{e}(\mathrm{t})| \mathrm{dt}
$$

where $\mathrm{T}$ represents the simulation time.

\section{Simulating the optimal fuzzy $P D+I$ controller}

The random impacts resulting from velocity fluctuations and road unevenness subject the car to vertical accelerations which bother and tire the passengers. The bumpiness of the road can be expressed by different models. In this research, a road with a sinusoidal bulge and a two-level road are the two models of road unevenness that have been used for the simulation of road unrests. In addition, the road unrests have been observed in two separated inputs; hence, the controller systems must reply appropriately to two road inputs, which means to each road input separately. In the simulation, it is supposed that the vehicle moves at a fixed velocity and that the road is completely rough. Figure 8 shows the input of a sinusoidal bulge and Figure 9 shows the two-level road inputs. The specifications considered for the genetic algorithm are presented in Table 5. The results of genetic algorithm for the road input of type I are listed in Table 6; the results for the road input of type II are shown in Figure 7.

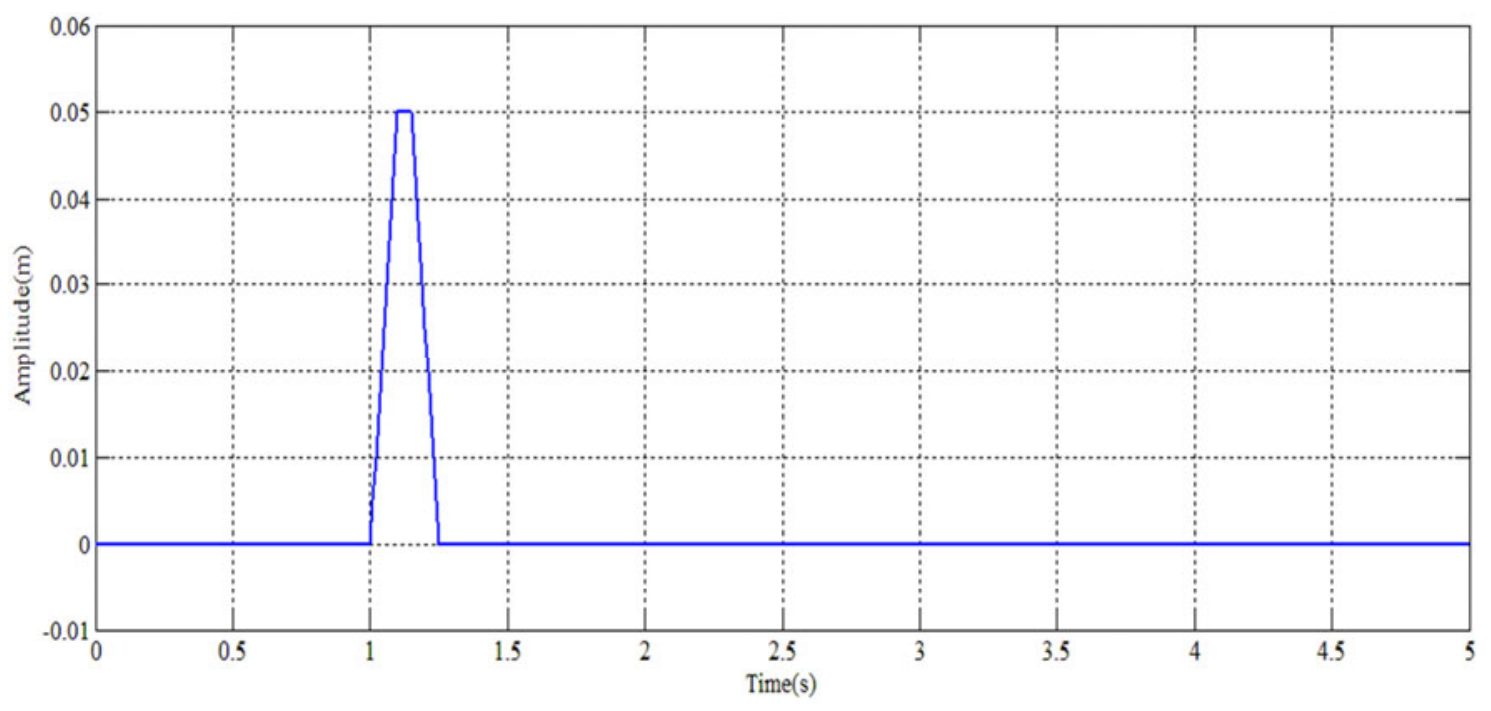

Fig. 8 Type I of the road input 


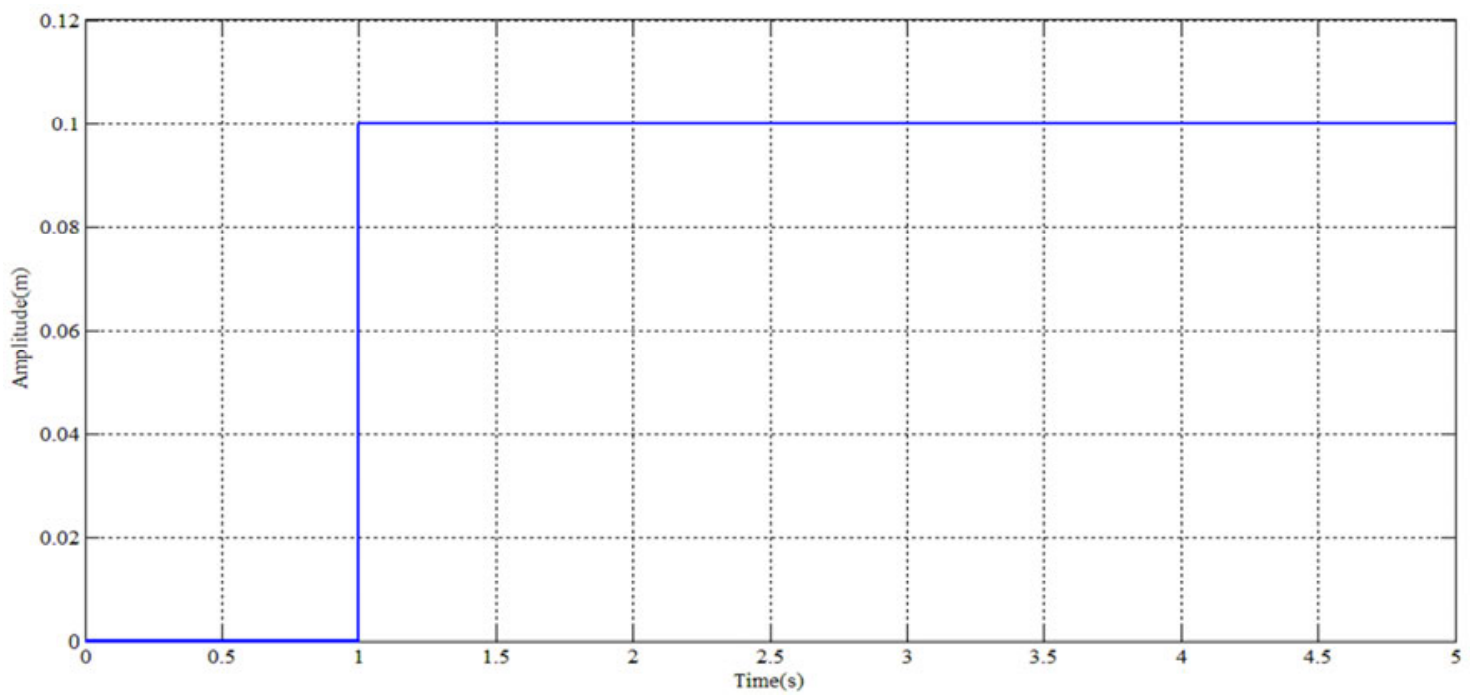

Fig. 9 Type II of the road input

Table 5 The specifications of the genetic algorithm

\begin{tabular}{|c|c|c|}
\hline Value & Definition & Parameter \\
\hline 20 & Population size & Population size \\
\hline 10 & Chromosome length & Chromosome length \\
\hline 0.7 & Rate or probability of copulation & Crossover probability \\
\hline 0.05 & Rate or probability of mutation & Mutation probability \\
\hline
\end{tabular}

Table 6 The amount of scaling coefficients for the input of type I

\begin{tabular}{|c|c|c|}
\hline $\mathrm{G}_{\mathrm{o}}$ & $\mathrm{G}_{\mathrm{ce}}$ & $\mathrm{G}_{\mathrm{e}}$ \\
\hline 0.169 & 4.969 & 4.914 \\
\hline
\end{tabular}

Table 7 The amount of scaling coefficients for the input of type II

\begin{tabular}{|c|c|c|}
\hline $\mathrm{G}_{\mathrm{o}}$ & $\mathrm{G}_{\mathrm{ce}}$ & $\mathrm{G}_{\mathrm{e}}$ \\
\hline 1.541 & 1.926 & 0.929 \\
\hline
\end{tabular}

\section{Results and discussion}

In this section, the performance of the proposed controller is evaluated and compared with that of three separate controllers (PID, fuzzy, and fuzzy PID). The velocity of the vehicle body increases due to the impact resulting from the vehicle hitting a road level irregularity of the type of a sinusoidal bulge (first model). Figure 10 shows variations in the vehicle body velocity. Figure 10 shows that the performance of the OFPD+I controller is better than that of the other controllers and the uncontrolled system. The Integral Absolute Error (IAE) criterion for the changes in the vehicle body velocity for the road input of type I is illustrated in Table 8. This criterion for each examined system is computed using equation 7. The results presented in Table 8 are illustrated in Figure 11.

$$
\operatorname{IAE}(V)=\int_{0}^{5}|V(t)| d t
$$




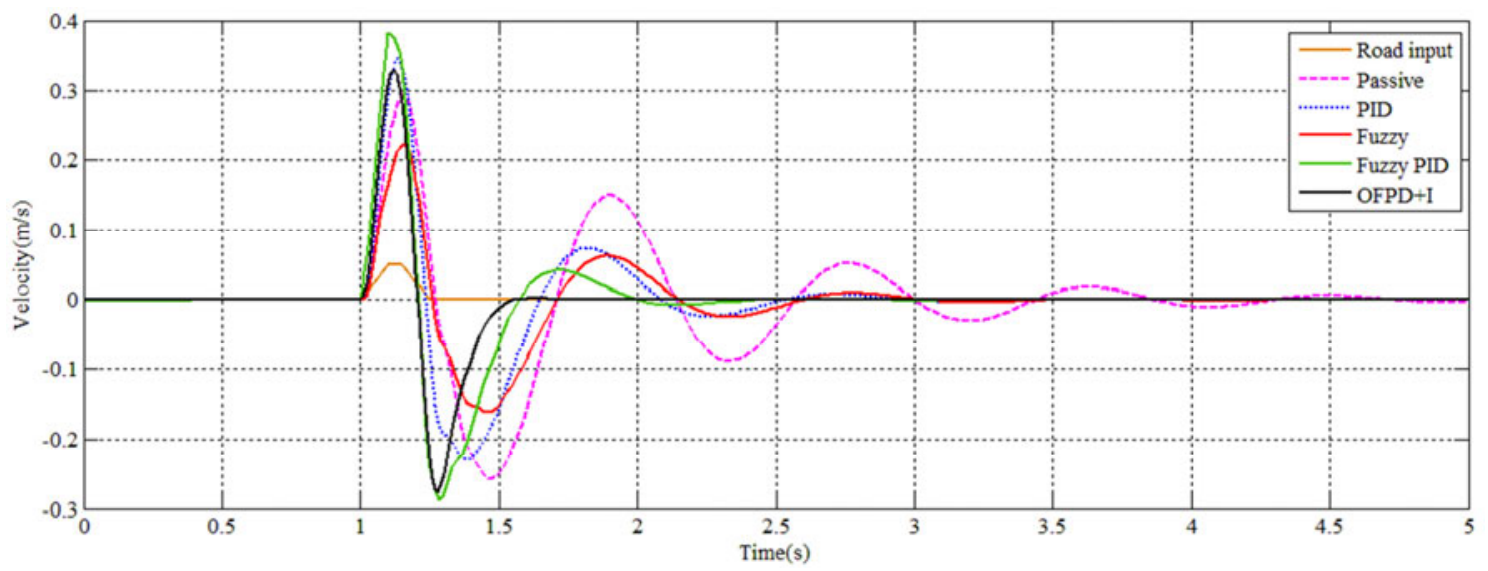

Fig. 10 Changes in the velocity of the vehicle body due to impact (road input of type I)

Table 8 Comparison of the IAE criterion of vehicle body velocity changes in the type I input

\begin{tabular}{|c|c|c|c|c|c|}
\hline Controller & Passive & PID & Fuzzy & Fuzzy PID & OFPD+I \\
\hline IAE $(V)$ & 0.2117 & 0.1347 & 0.1063 & 0.1162 & 0.07711 \\
\hline
\end{tabular}

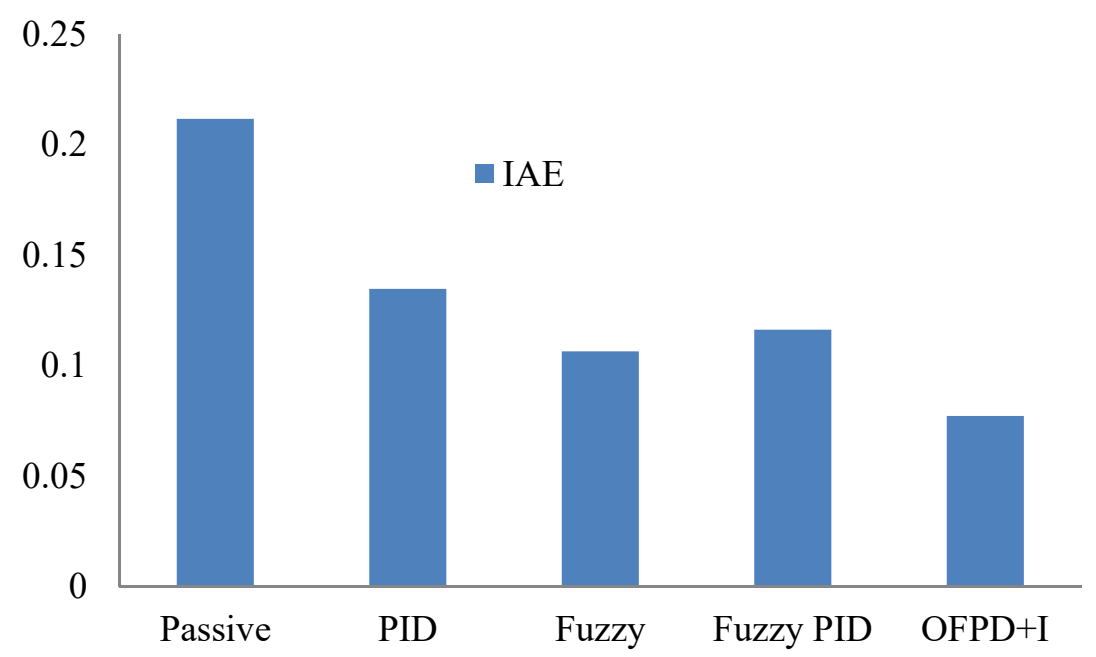

Fig. 11 Compare the performance of the controller according to the $\operatorname{IAE}(V)$ criteria in the type I input

Figure 11 clearly shows that the performance of the OFPD+I controller in changing the vehicle body velocity is superior to the others with regards to the IAE criterion. The IAE(V) criterion values for the OFPD $+\mathrm{I}$ and fuzzy PID controllers and for the passive system are $0.1014,0.1412$ and 0.4059 , respectively. The vehicle body is displaced by the impact resulting from the vehicle hitting a road level irregularity; the trend of these displacements is illustrated in Figure 12. 


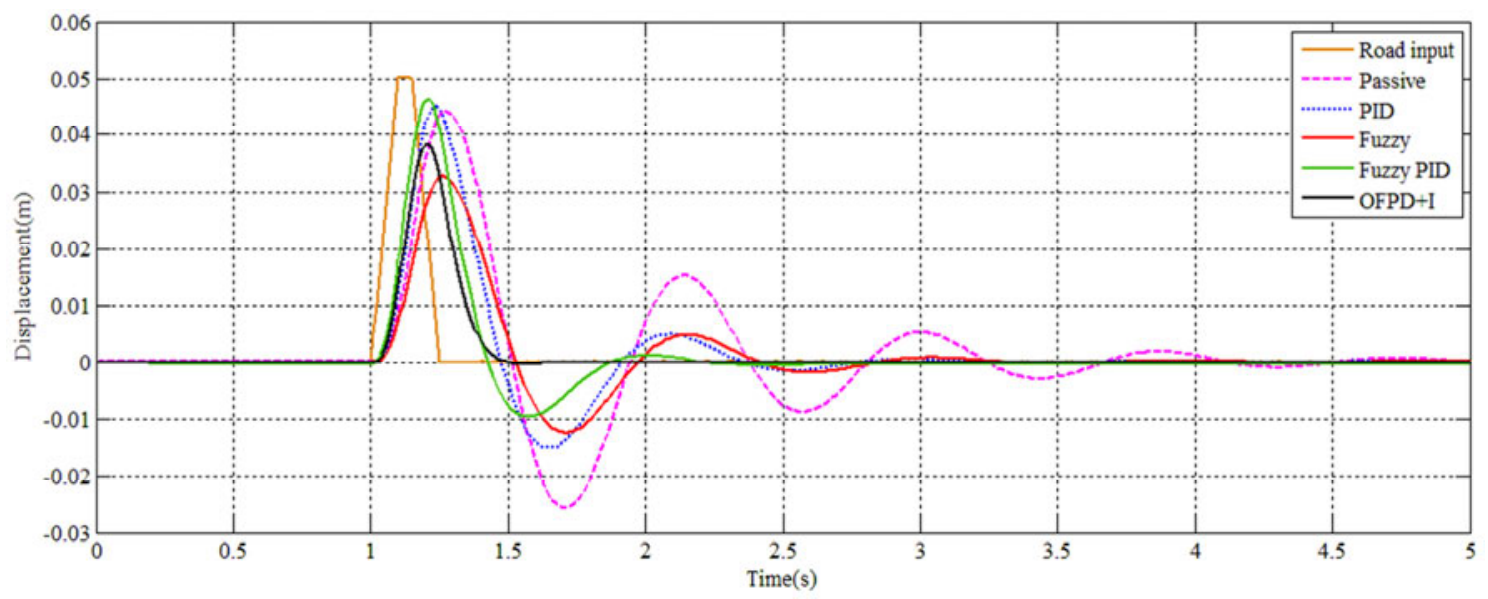

Fig. 12 Changes in the vehicle body displacement due to impact (road input of type I)

Figure 12 clearly shows the advantage of the OFPD+I controller over the other systems in controlling the vehicle body displacement changes. By controlling the displacements of the vehicle body, the danger caused by its vertical vibrations is also reduced. An analysis of the controller responses to the changes in the vehicle body displacement (shown in Figure 12) indicates that the OFPD $+\mathrm{I}$ controller behaved very appropriately in this regard. The IAE criterion for the changes in the vehicle body displacement for the road input of type I is shown in Table 9 for each investigated system. Equation 8 is used to compute this criterion. Figure 13 shows a column chart of the results presented in Table 9.

$$
\operatorname{IAE}(\mathrm{r}-\mathrm{y})=\int_{0}^{5}|(\mathrm{r}-\mathrm{y})| \mathrm{dt}
$$

Table 9 Comparison of the IAE criterion changes in the vehicle body displacement in the type I input

\begin{tabular}{|c|c|c|c|c|c|}
\hline Controller & Passive & PID & Fuzzy & Fuzzy PID & OFPD+I \\
\hline IAE(r-y) & 0.03038 & 0.01708 & 0.01697 & 0.01253 & 0.00776 \\
\hline
\end{tabular}

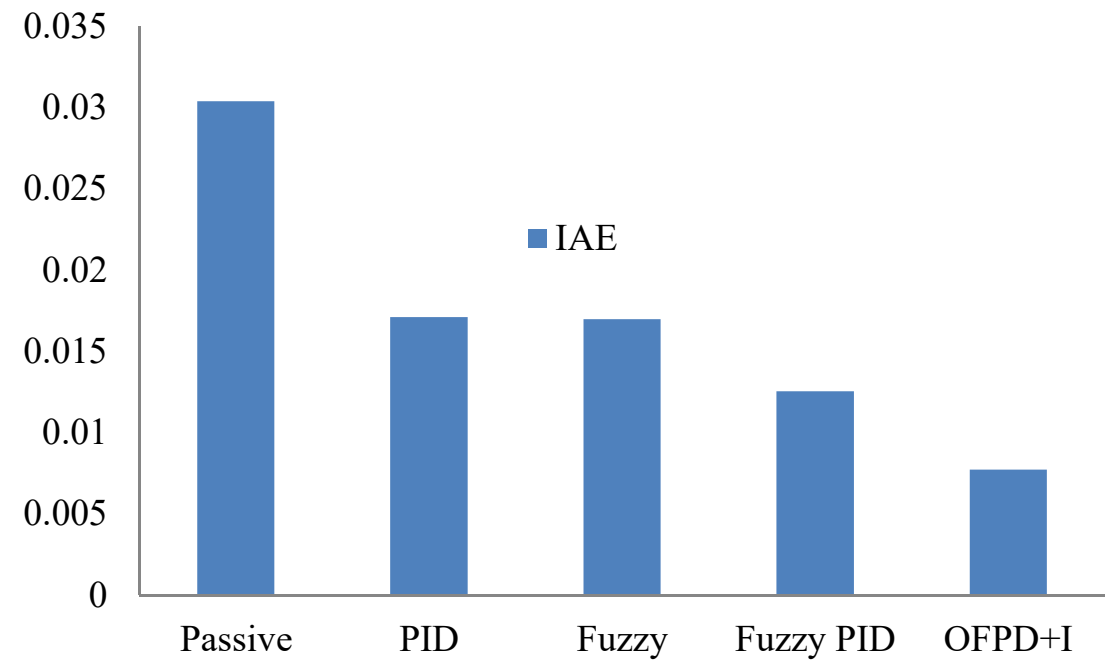

Fig. 13 Compare the performance of the controller according to the IAE (r-y) criteria in the type I input

Figure 13 indicates that, with regards to the reduction in the values of the IAE(r-y) criterion, the proposed controller is ranked higher than the other controllers. Considering the IAE criterion for vehicle body displacements at the moment of impact resulting from the vehicle hitting a road level irregularity, the OFPD + I controller has a superior performance to those of the other systems. The values of the IAE (r-y) criterion for the OFPD+I and fuzzy 
PID controllers and for the passive system are $0.01037,0.01871$, and 0.05273 , respectively. The magnitudes of forces used by the controller in the road input of type I are illustrated in Figure 14.

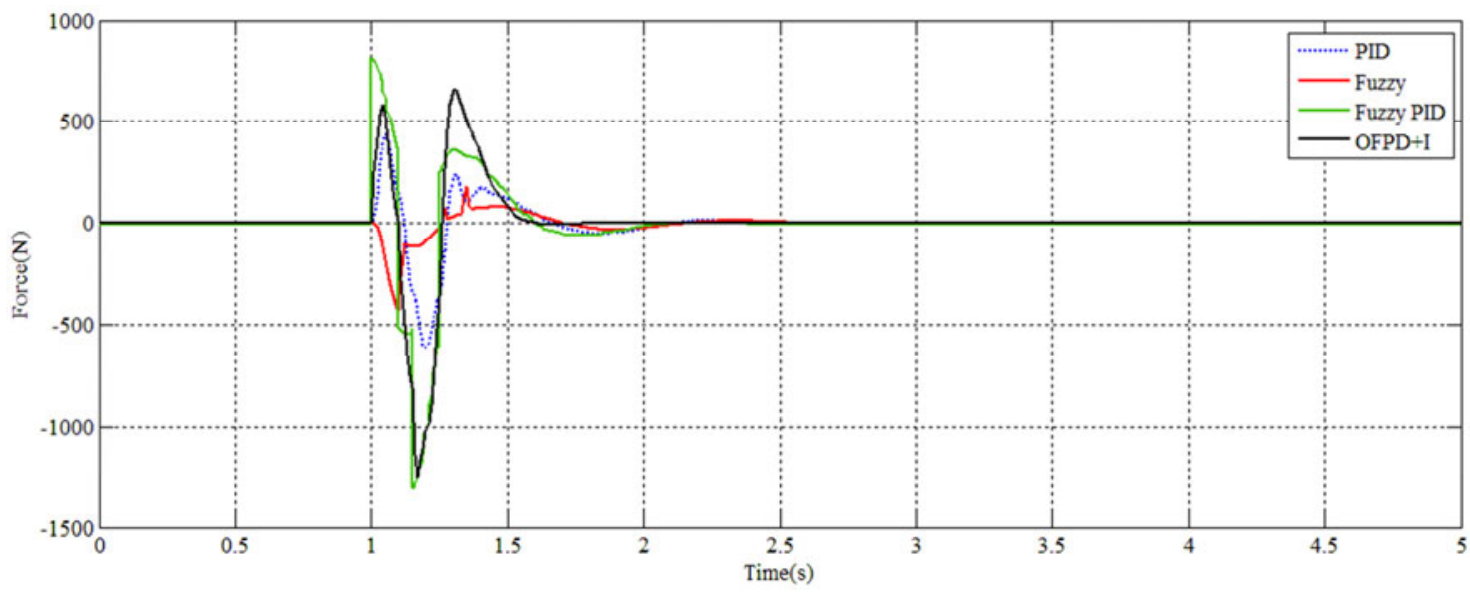

Fig. 14 The force used by the controller in the type I input

Figure 14 shows that the loop phenomenon in the control force of the OFPD+I controller is less observable than that of the other systems. This characteristic is very important in practice and it provides more leeway in choosing the system actuators. Table 10 shows a comparison of the controlling force of the controllers in the first model.

Table 10 Comparison of controlling forces in the type I input

\begin{tabular}{|c|c|c|c|c|}
\hline PID & Fuzzy & Fuzzy PID & OFPD+I & Controller \\
\hline 444 & 185 & 816 & 660 & Maximum positive force (+F) \\
\hline 618 & 432 & 1309 & 1253 & Maximum negative force (-F) \\
\hline
\end{tabular}

The body of the vehicle accelerates also by the two-surface change to the two-level road type (second model). Figure 15 illustrates the amount of vehicle body velocity changes.

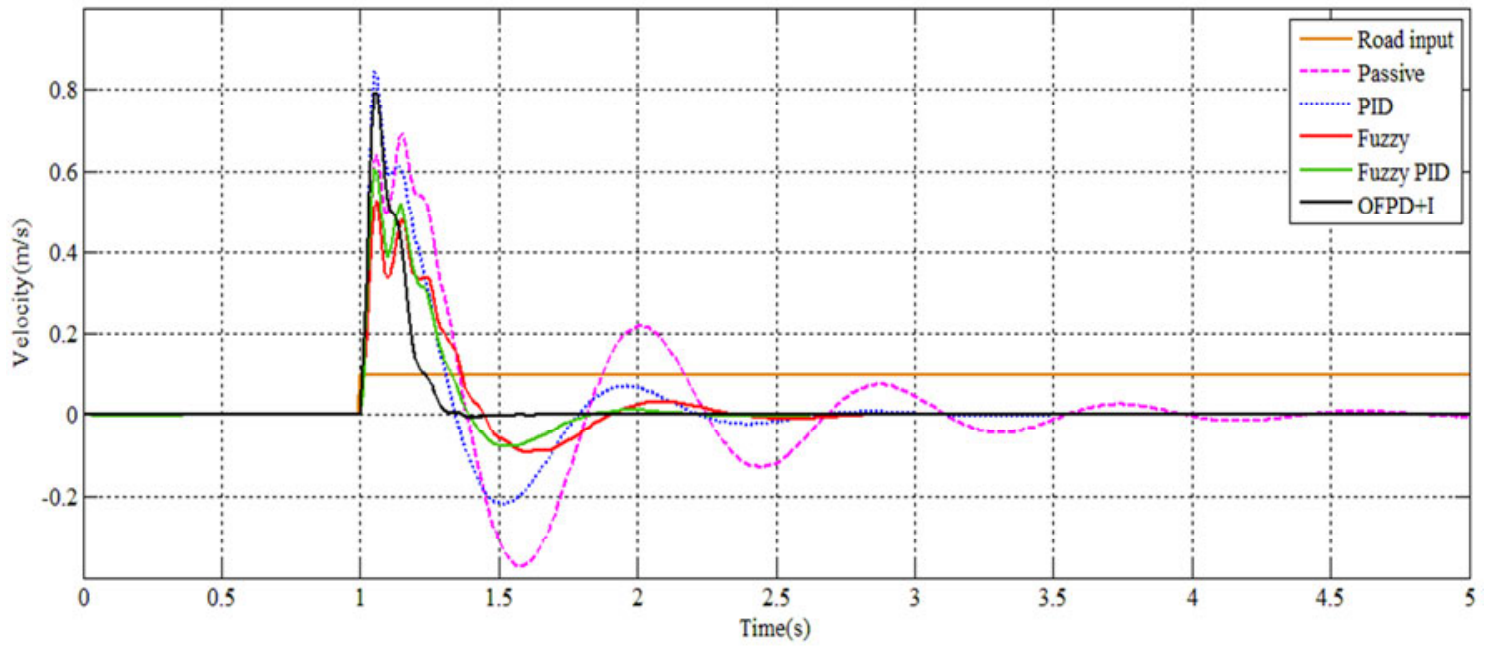

Fig. 15 Changes in the vehicle body velocity due to impact (road input of type I)

Figure 15 shows that the OFPD+I controller has a lesser degree of control than the other controllers and the passive system. The IAE criterion for the vehicle body velocity change in the second model input is illustrated in Table 11 for each system. Equation 7 is used for computing this criterion. The results presented in Table 11 are shown in Figure 16. 
Table 11 Comparison of the IAE criterion of the vehicle body displacement changes in the type II input

\begin{tabular}{|c|c|c|c|c|c|}
\hline Controller & Passive & PID & Fuzzy & Fuzzy PID & OFPD+I \\
\hline $\operatorname{IAE}(\mathrm{V})$ & 0.4059 & 0.2318 & 0.1579 & 0.1412 & 0.1014 \\
\hline \multicolumn{6}{|c|}{0.45} \\
\hline \multicolumn{6}{|c|}{0.4} \\
\hline \multicolumn{6}{|c|}{0.35} \\
\hline \multicolumn{6}{|c|}{0.3} \\
\hline \multicolumn{6}{|c|}{0.25} \\
\hline \multicolumn{6}{|c|}{0.2} \\
\hline \multicolumn{6}{|c|}{0.15} \\
\hline \multicolumn{6}{|c|}{0.1} \\
\hline \multicolumn{6}{|c|}{0.05} \\
\hline & Passive & PID & dzzy & OFPD & \\
\hline
\end{tabular}

Fig. 16 Compare the performance of the controller according to the IAE (V) criteria in the type II input

In Figure 16 one can easily notice that the suggested controller, from the aspect of decreasing the IAE (V) has the best score of all the controllers. And also the vehicle body has been moved due to this impact. The amount of vehicle body displacement changes for the type II input are shown in Figure 17.

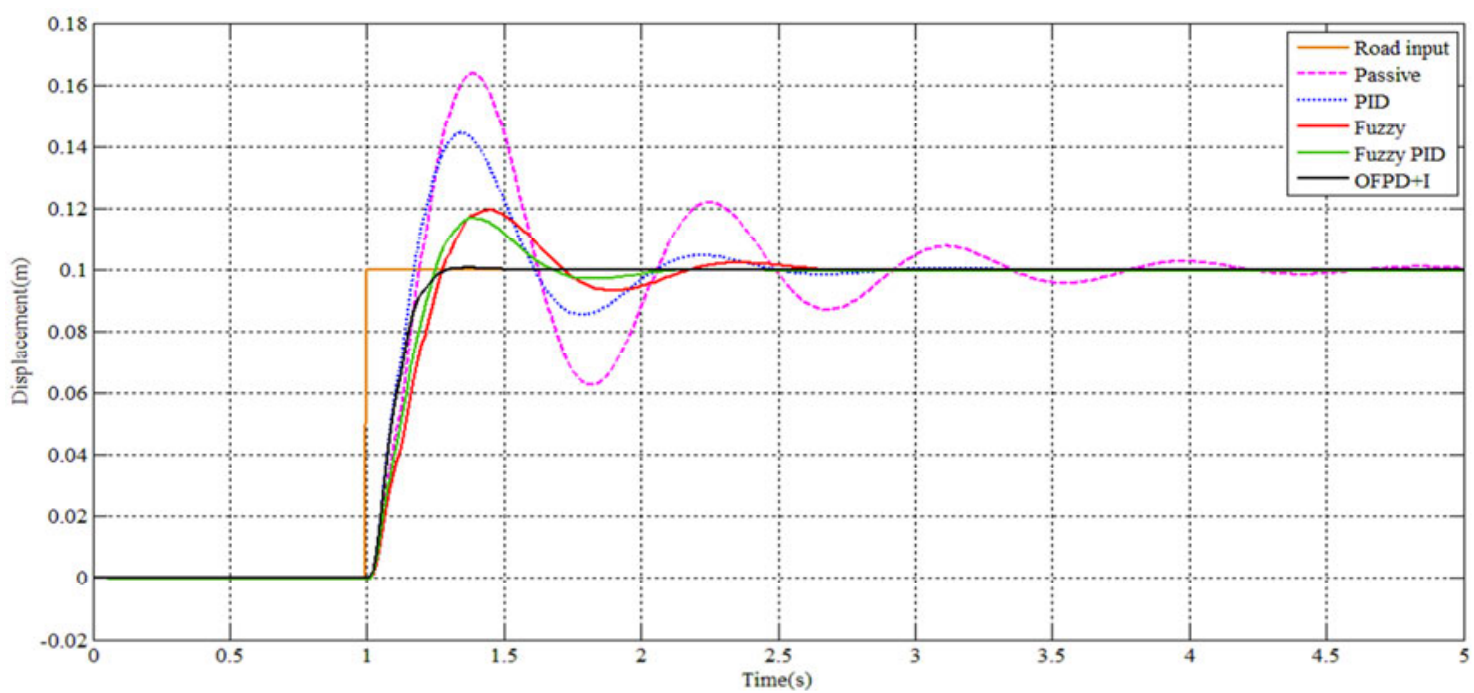

Fig. 17 Changes in the vehicle body displacement due to impact (road input of type I)

The advantage of the OFPD+I controller over the other systems with respect to vehicle body changes is shown in Figure 16. The IAE criterion changes in the vehicle body movement in each system for the type II road input is shown in Table 12. Equation 8 is used for computing this criterion. Figure 18 shows a column chart of the numerical results presented in Table 12.

Table 12 Comparison of the IAE criterion of the vehicle body displacement changes in the type II input

\begin{tabular}{|c|c|c|c|c|c|}
\hline Controller & Passive & PID & Fuzzy & Fuzzy PID & OFPD+I \\
\hline IAE(r-y) & 0.05273 & 0.02699 & 0.02205 & 0.01871 & 0.01037 \\
\hline
\end{tabular}




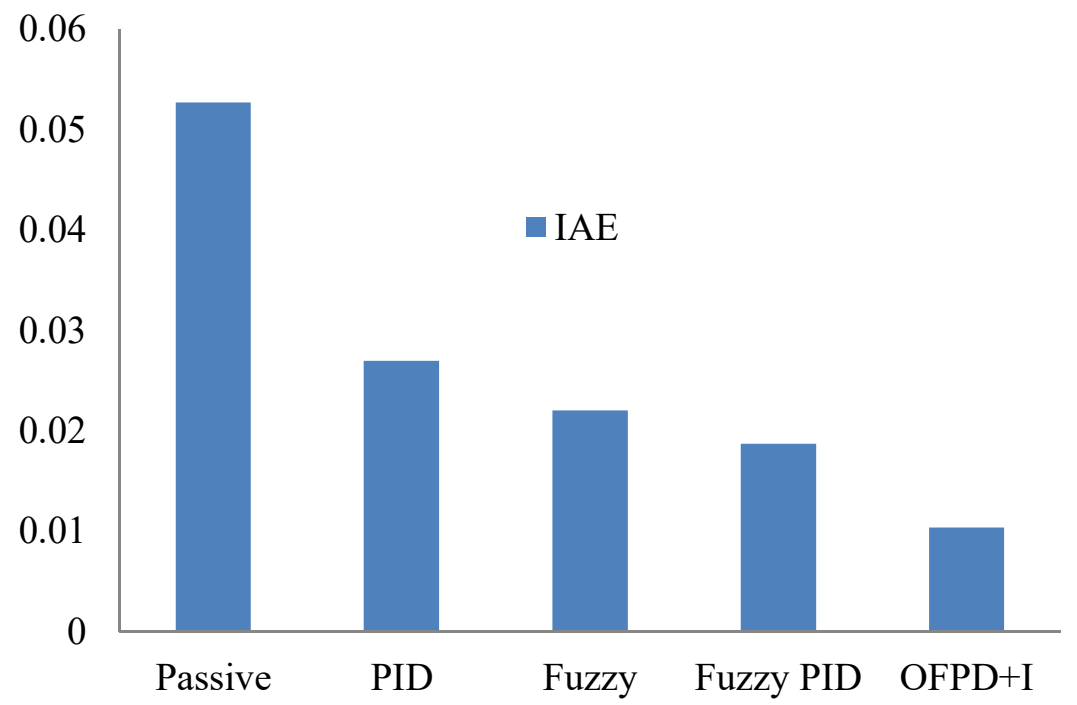

Fig. 18 Compare the performance of the controller according to the IAE (r-y) criteria in the type II input

From Figure 18, it is clear that the suggested controller from the aspect of decreasing $\mathrm{IAE}(\mathrm{r}-\mathrm{y})$ has the best score of all the controllers. The magnitude of forces used by the controllers in the type II road input is shown in Figure 19. Table 13 shows a comparison of the controlling force of the controllers in the second model.

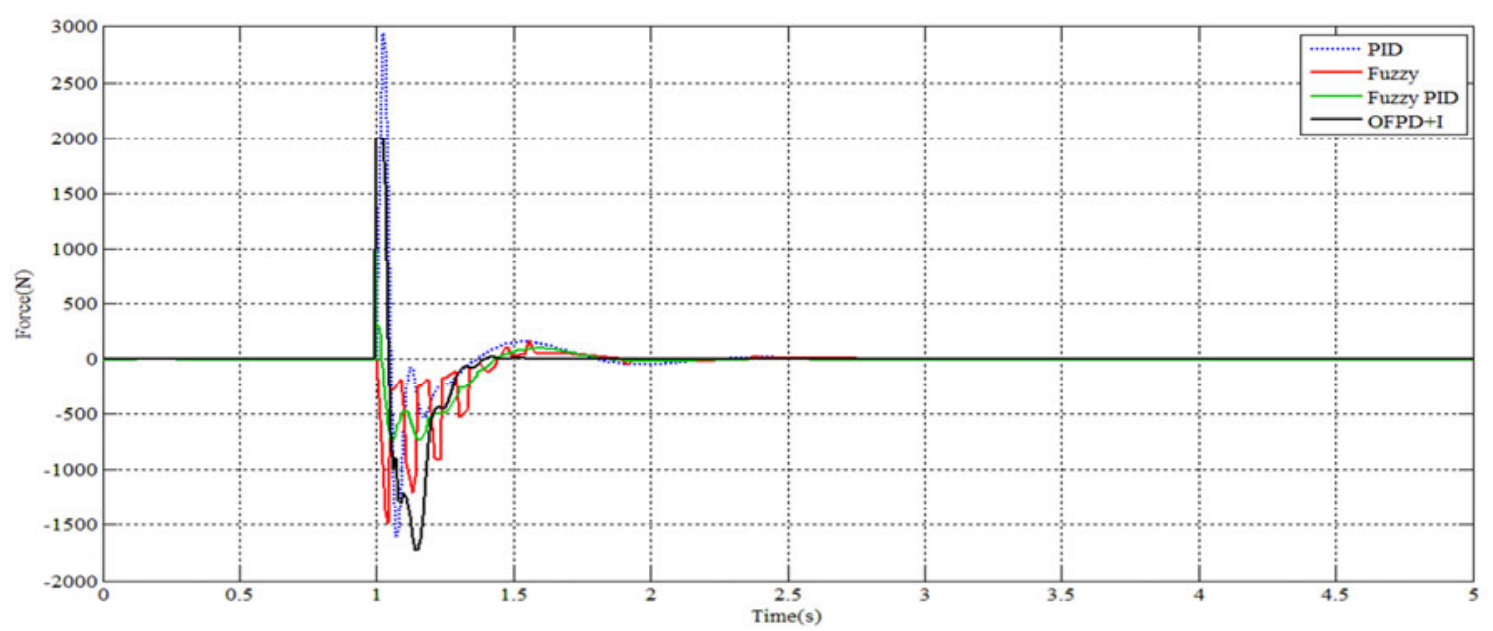

Fig. 19 The controlling force used by the controllers in type II

Table 13 Comparison of the controlling force in the second model.

\begin{tabular}{|l|l|l|l|l|}
\hline PID & Fuzzy & Fuzzy PID & OFPD+I & Controller \\
\hline 2950 & 166 & 2000 & 2000 & Maximum positive force (+F) \\
\hline 1608 & 1482 & 742 & 1728 & Maximum negative force (-F) \\
\hline
\end{tabular}

As we have seen in the figures related to the velocity changes and the vehicle displacement in the second model of road input, the performance of the OFPD+I controller is better than those of the other controllers. To achieve that, a stronger controlling force has been exerted, as shown in Table 13. In addition, Figure 18 shows that the convoluted phenomenon in the controlling forces of OFPD+I is less observable than the controlling force of the other systems. This characteristic is really important in practice as one will act more freely in choosing system simulators. 


\section{Conclusion}

In this research, the behaviour of the optimal fuzzy PD+I controller in controlling the active suspension system of a quarter car model for two separated input was investigated. For this purpose, and for demonstrating the effectiveness of the OFPD $+\mathrm{I}$ controller, the performance of this controller was compared with that of three separate controllers (PID, fuzzy, and fuzzy PID) as well as an uncontrolled suspension system, with respect to the parameters of vehicle body velocity and displacement and also the applied control force. The results indicate the superiority of the OFPD+I controller relative to the other controllers. In the sinusoidal bulge input (the type I input), in the integral absolute error criterion for the changes in the vehicle body velocity in each system, the OFPD+I controller has a significant advantage; the value of IAE(V) for the OFPD+I controller is 0.07711 and for the passive system it is 0.2117 . Considering the IAE criterion, the performance of the OFPD+I controller in controlling the vehicle displacements in each system for the type I input is also superior. The value of the IAE(r-y) criterion for the OFPD + I controller is 0.00776 and in the passive system it is 0.03038 . Since by reducing the displacements of the vehicle body, the danger due to its vertical vibrations is also reduced, an analysis of controller behaviour patterns in the results related to the changes in the vehicle body displacement indicates that the OFPD $+\mathrm{I}$ controller behaves very well also in this case. The comparison between the controlling forces in the type I input used by the controller shows that the OFPD+I controller spends more energy than the PID and fuzzy controllers. However, despite using a greater amount of force, the proposed controller has a very good performance in controlling the vehicle body velocity and displacement. By analysing the responses of control forces, it is observed that the loop phenomenon in the control force of the OFPD $+\mathrm{I}$ controller is of a lesser degree than that of other control systems. This feature is very important in practice, and it provides more freedom in choosing the system actuators. And also, in the road input of type II, that is a two-level road by height of $10 \mathrm{~cm}$, all the results show the advantages of suggested control.

\section{REFERENCES}

[1] Zapateiro M., Luo N., Karimi H.R., Vehí J. Vibration control of semi active suspension system using neural network and backsteppingtechniques, Mechanical System and Signal Processing, Vol. 23, Issue 6, pp. 1946-1953, 2009. DOI: 10.1016/j.ymssp.2008.10.003

[2] Priyandoko G., Mailah M., Jamaluddin H. Vehicle active suspension system using skyhook adaptive neuro active force control, Mechanical System and Signal Processing, Vol. 23, Issue 3, pp. 855-868, 2009. DOI: 10.1016/j.ymssp.2008.07.014

[3] Khajavi M.N., Abdollahi V. Comparision between optimized passive vehicle suspension system and semi active fuzzy logic controlled suspension system regarding ride and handling, Transaction on Engineering Computing and Technology,Enformatika, Vol. 19, pp. 57-61, 2007.

[4] Hada M.K., Menon A., and Bhave S.Y. Optimisation of an active suspension force controller using gentic algorithm for random input, Defence Science Journal, Vol. 57, Issue 5, pp. 691-706, 2007. DOI: $10.14429 / \mathrm{dsj} .57 .1806$

[5] Li H., Yu. J. Adaptive sliding mode control for nonlinear active suspension vehicle systems using T-S fuzzy approach, Transactions on Industrial Electronics, Vol. 60, Issue 8, pp. 3328-3338, 2013. DOI: 10.1109/TIE.2012.2202354

[6] Shiao Y., Nguyen Q.A., and Lai C.C. A novel design of semi active suspension system using magneto rheological damper on light weight vehicle, Transactions of The Canadian Society for Mechanical Engineering, Vol. 37, Issue 3, pp 723-732, 2013.

[7] J. Wang H., Wang and L. Guo. Simulation for vehicle active suspension control based on different feedback parameters, Journal of Theoretical and Applied Information Technology, Vol. 47, Issue 3, pp 1008-1014, 2013.

[8] Devdutt, Aggarwal M.L. Fuzzy logic controller of a semi-active quarter car system, Journal of Mechanical, Aerospace, Industrial and Mechatronic Engineering, Vol. 8, Issue 1, pp 163-167, 2014. 
[9] Tabatabaei S.H.R., Kofigar H.R. Design optimal fuzzy PID controller for suspension system, First International Conference on Mechanical Engineering, Iran, 2014.

[10] Yi, SooYeong.,Myung Jin Chung. Robustness of fuzzy logic control for an uncertain dynamic system, IEEE Transactions on Fuzzy System. Vol. 6, Issue 2, pp 216-225, 1998.

[11] Priyandoko G., Moilah M.,JamaluddinH.Vehicle active suspension system using skyhook adaptveneuro active force control, Mechanical System and Signal Processing, Vol. 23, Issue 3, pp 855-868, 2009. DOI: 10.1016/j.ymssp.2008.07.014

[12] Centin S., Demir O. Fuzzy PID controller with coupled rules for a nonlinear quarter car model, Proceedings of World Academy of Science: Engineering \& Technology, Vol. 41, pp 238-241, 2008.

[13] Demir O., keskin I., Cetin S.Modeling and control of a nonlinear half-vehicle suspension: a hybrid fuzzy logic approach, Nonlinear Dynamics, Vol. 67, Issue 3, pp 2139-2151, 2012. DOI: $10.1007 / \mathrm{s} 11071-011-0135-\mathrm{y}$

[14] Rashid M.M.,Hussain M.A., Abad Rahim N.,Momoh J.S. Development of a semi-active car suspension control system using magneto-rheological damper model, International Journal of Mechanical and Materials Engineering, Vol. 2, Issue 2, pp 93-108, 2007.

[15] Zifan F., Wenhui S., Daojia D., Bingfei X. Qingsong H., Kongde H. Semi-active suspension of a fullvehicle model based on double-loop control, Procedia Engineering, Vol. 16, pp 428-437, 2011. DOI: 10.1016/j.proeng.2011.08.1107

Submitted: $\quad 08.4 .2016$

Accepted: $\quad 01.9 .2016$
Meisam Ghafouri

Department of Mechanical Engineering,

Majlesi Branch, Islamic Azad University, Isfahan, Iran

Saeed Daneshmand

Department of Mechanical Engineering, Majlesi Branch, Islamic Azad University, Isfahan, Iran

Corresponding author

S.daneshmand@iaumajlesi.ac.ir 